\title{
Spatial Diffusion of Civil Liberty
}

\author{
Coro Chasco $^{\mathrm{a}, \mathrm{b}, \not}$, Maricruz Lacalle-Calderon ${ }^{\mathrm{c}}$, Javier Alfonso-Gil $^{\mathrm{d}}$ \\ aUniversidad Autónoma de Madrid \\ ${ }^{\mathrm{b}}$ Nebrija University \\ $\bowtie$ coro.chasco@uam.es "Corresponding author \\ ${ }^{\mathrm{c}}$ Universidad Autónoma de Madrid \\ $\bowtie$ maicu.lacalle@uam.es \\ dUniversidad Autónoma de Madrid \\ $\bowtie$ javieralfonsogil@gmail.com
}

\begin{abstract}
This paper studies the existence of spatial diffusion of civil liberty among neighboring countries. For that purpose, we first combine different exploratory space-time data analysis approaches to find that this phenomenon is spatially clustered and that a convergence process is at work among the world countries from 1985 to 2010, with a structural change by the end of the Twentieth century mainly due to the appearance of the Internet. Second, we specify a spatial autoregressive panel data model for a sample of 130 countries, for 1985-2000, and 172 countries, for 2000-2010. Results provide evidence for spatial diffusion of civil liberty, though it is not constant along this time span. The spreading rate is 0.34 in the first sub-period. After 2000, it reduces to 0.21; that is, countries only "catch" $21 \%$ of the average changes in their neighbors' civil liberty levels. Additionally, religious culture, urban agglomeration and GDP explain the levels of civil liberties in the world.
\end{abstract}

Article History: Received: September 302020 / Revised: January 132021 / Accepted: April 132021 Keywords: Civil liberty; Spatial diffusion; Religion; Human agglomeration; Internet; Spatial econometrics

JEL Classification: C21, C31, D02, O43, P48 


\section{Introduction}

According to Berlin's (1958) seminal article, civil liberty or "negative liberty" is the individual right to make decisions within a given vital space without interference. It defines the limits between the state and the individual and, within those limits, guarantees the right for human beings to not have their field of action invaded. Along with this concept, Berlin (1958) also defined "positive liberty" (political rights or democracy) as the right of each individual to choose their representatives or to run for election to any public position in the community.

Built on Berlin's conceptual work, this paper focuses on civil liberty in order to explain its spatial diffusion. There are not many references in the literature using spatial econometrics to study the contagion of freedom. The principal authors are O'Loughlin et al. (1998), Ward and Gleditsch (2008) and Leeson and Dean (2009), who have investigated the spread of democracy among countries, Leeson et al. (2012) and Sobel and Leeson (2007), who have studied the spread of economic freedom, Sobel et al. (2010) who have analyzed media freedom spread, and Kelejian et al. (2013), who analyze the spatial spillovers of institutions and governance. We differ from all this literature by focusing on the spread of specifically civil liberty, which is not the same concept as democracy or any other type of freedom (Aixalá and Fabro, 2009 and in a deeper analysis, Alfonso-Gil et al., 2014). To our knowledge, there are no empirical studies on the spatial diffusion of civil liberty. ${ }^{1}$

Consequently, the aim of this paper is to study whether civil liberty is a transmissible phenomenon across countries. For that purpose, we first combine exploratory space-time data analysis (ESTDA) approaches - Kernel distributions and directional LISA graphs - to detect spatial clusters and a convergence process across countries in terms of civil liberties. We estimate the spreading rate of civil liberty using spatial econometric models, which are specifically designed to measure spatial dependence. In other words, this paper explores if the level of civil liberty in neighboring countries explains the level of civil liberty in any country. Furthermore, this paper studies other factors conditioning civil liberty. To these purposes, we use the Civil Liberty Gastil index from Freedom House (2012) as the endogenous variable in a two-way fixed-effects spatial autoregressive panel data model estimated with a sample of 130 countries for the period 1985 to 2000, and with an expanded sample of 172 countries for the years between 2000 and 2010. The results show that civil liberty does spread across geographical space. There is indeed a positive and very significant spreading rate of civil liberty across neighboring countries. Nevertheless, this rate is not homogeneous along the whole period due to the existence of a structural change

\footnotetext{
${ }^{1}$ Beyond spatial techniques, there are few empirical studies of the role played by civil liberty (Alfonso-Gil et al., 2014; Benyishay and Betancourt, 2010; Kormendi and Meguire, 1985; Isham et al., 1997; King and Levine, 1993). Some authors such as Rhue and Sundararajan (2014), Curran and Wherry (2003), Heid et al. (2012) and Barro (1999) have used civil liberty in their models, but only as a proxy for studying democracy. There is also a close vast literature studying the relationship between economic freedom and growth (De Haan and Sturm, 2000; Heckelman, 2000; Carlsson and Lundström, 2002; Dawson, 2003; Cole, 2003; Doucouliagos and Ulubasoglu, 2006; Justesen, 2008; Compton et al., 2011; among others). Other authors have gone into the relation between democracy and economic growth where there is a considerable debate around two opposing hypotheses: the Modernization Hypothesis (Barro, 1996; Gundlach and Paldam, 2009; Heid et al., 2012; among others) and the Critical Junctures Hypothesis (Acemoglu et al., 2008, 2009). Our paper is marginal to all these debates.
} 
at the end of the Twentieth Century because of the irruption of Internet: it is clearly higher for the first sub period (35\%) while it slows down to $21 \%$ after the year 2000, mainly due to this phenomenon. In addition, the results indicate that religion culture, urban agglomerations in the physical city and the digital city, and per capita GDP, as well as other explanatory control variables, are also statistically significant and may also explain the level of civil liberty in any country.

This paper proceeds as follows. Section 2 analyses the sources of spatial diffusion in civil liberty, as well as other conditioning factors of civil liberty. Section 3 describes and explores the data. Section 4 explains and justifies the empirical spatial panel data model. Section 5 explains the most relevant econometric results and Section 6 concludes.

\section{Spatial Diffusion and Other Determinants of Civil Liberty}

This paper analyses the impact of spatial diffusion in civil liberty worldwide. Additionally, we consider some other conditioning factors proposed in the literature such as religious culture, urban agglomerations (or what we have called "the city factor"), GDP per capita, population density, commonest languages, origin of the legal system and some physical geography indicators.

\section{A) Territorial contagion}

Spatial or territorial diffusion is what Sobel and Leeson (2007) and Leeson and Dean (2009) call the "geography variable". Historically, civil liberty did not appear everywhere at the same time: from a focal point, there was a subsequent territorial "contagion". This focal point was basically France with the proclamation of civil rights in the late eighteenth century (Palmer, 1959; Nair, 2011), though one century before, the Netherlands and England had already created and molded the rules leading to the full incorporation of the human being into society (North and Weingast, 1989; North, 1995). With hindsight, the lack of clear borders in Europe, as well as the existence of similar legal and cultural customs, facilitated the territorial spread of these new ideas, mainly by means of commerce and population migrations (Sobel and Leeson, 2007). From the European epicenter, civil liberty was progressively exported to the rest of the world.

The diffusion and contagion of any idea or event, and therefore civil liberty, will be imitated and reflected in neighboring territories through geographic channels (Sobel and Leeson, 2007; Leeson and Dean, 2009; Leeson et al., 2012). This concept of spatial diffusion or "geographic spread" has been recently used in the literature as related with the democratic "domino effect" (Leeson and Dean, 2009), media freedom (Sobel et al., 2010), institutions and polity spatial spillovers and clustering (Ward and Gleditsch, 2008; Kelejian et al., 2013), social networks (Centola and Macy, 2007) and even with financial crisis (Dornbusch et al., 2000; Peckham, 2013), in which contagion has been defined as the "cross-country transmission of shocks or the general cross-country spillover effects". Following this latter definition, the term "spatial diffusion" will be used in this paper - with reference to civil liberty — as a synonym for cross-country (inter-country instead of intra-country) spillovers. Inter-nation more or less formal connections could be decisive for the transmission process of civil liberty to become definitely established in a territory, since interactions between countries clearly shape their social, economic and political agenda. Though

\section{c: PUCP}


there are diverse ways in which different countries are linked to one another, it is conceivable that any one of these links alone could serve as a long-run conduit for the forces of civil liberty, as demonstrated by O'Loughlin et al. (1998), Rhue and Sundararajan (2014) and Lewczuk (2020). Close physical proximity may indicate similar cultures and strong ties among nations. Countries with strong relationships and similar cultures are more susceptible to all kinds of pressures from each other.

For this reason, we expect a spatial diffusion effect of civil liberty, in the sense that the level of civil liberty in any country depends on the levels of civil liberty in its neighboring countries.

\section{B) Other determinants of civil liberty}

In order to consider the most frequently used conditioning factors of freedom in the literature, our model includes some structural explanatory variables, such as religious culture, urban agglomerations and per capita GDP, joint to some other control explanatory variables like population density, commonest languages, origin of the legal system and some physical geography indicators.

Religious culture may be an important factor for acceptance of the principles underlying civil liberty on the part of the citizenry in any society. Recently, culture has been increasingly used as a major determinant of institutional change and growth in the academic literature (Tabellini, 2008). As explained by Natharaj (2011), the western philosophy of the "rights of man" was greatly influenced by the earlier Greek Stoics school of thought, as well as the writings of medieval Christian thinkers and modern philosophers, who stressed the humanness of the human being and tried to prove the superiority of natural law. Therefore, the idea of natural rights was strengthened by religious and socio-cultural factors. According to cultural theories, religion is a significant variable in explaining the ethic of a society, as well as trust and other characteristics that could be important in explicating the quality of institutional development (Landes, 1998; Weber, 2002), the quality of a government (La Porta et al., 1999; Haynes, 2013) and civil liberty and democracy (Lipset, 1994; Boone, 1996). Nevertheless, not all religion-based cultures and their philosophies have fostered the development of civil liberty in their respective countries. Some authors like Huntington (1996), Barro (1999) or Gundlach and Paldam (2009) claim that various expressions of Christianity - notably, Protestantism and Catholicism - have a propensity to be supportive of civil liberty, while other religions do not. Specifically, the Christian religion represents the origin of the individual seen as a subject of dignity (Greif, 2004; Minogue, 2012), which is a decisive moral force in the birth of civil liberty. Conversely, Islam, and particularly the Arab states, remains authoritarian since still offers a set of spiritual beliefs to govern society being incapable to dissociate religion from the political spheres (Wright, 1992) and no legitimacy is provided for autonomous social institutions at the national level (Eisenstadt, 1968). In the case of Asian societies, Buddhism and Confucianism (the predominant philosophies) may jeopardize civil liberties because their strong traditions of order, centralized power and discipline.

Urban agglomerations in the modern city are the natural location for new ideas to be propagated. They have constituted another powerful force in the emergence of civil liberties in Europe since the Middle Ages (De Long and Shleifer, 1993). The city, led by the bourgeoisie, has always 
been a great vehicle for change in society through ideas, opportunities and access to civil liberties (McCloskey, 2010). Nevertheless, during the last two decades, urban agglomeration or "the physical city" has been deeply transformed by the new technologies. The smart city or "the digital city" is now the new environment in which innovations, in general, and civil liberty in particular, develop and flow through Internet on a scale and at a speed never seen before (Aurigi, 2005; Chokoshvili, 2011). The Internet has been defined as the new "digital public square", since lower communication costs enable it to supplement or substitute "built-space" public square gatherings, in which individuals express and eventually fulfil their collective beliefs and opinions (Chwe, 2003; Zhuo et al., 2011). Maybe for these reasons, indicators such as urbanization rate, which is a proxy for the physical city, does not seem to be - at present - as significant as an explanatory variable of the different levels and evolution of civil liberty throughout the world (Barro, 1999; Curran and Wherry, 2003; Tausch and Heshmati, 2010; Pick et al., 2020). However, if we express urban agglomeration by the ratio of Internet users, the result becomes extremely significant. Internet and, in general, the social media technologies, which express the new concept of the digital city, emerge as the prominent engine fostering the emergence and diffusion of ideas (Centola and Macy, 2007; Bond et al., 2012; Rhue and Sundararajan, 2014). That is to say, the "city factor", which adapts to the changing conditions of human civilization, remains an essential vehicle for the initial transmission and subsequent institutionalization of new ideas and values.

Economic growth and standard of living, which is usually expressed as Gross Domestic Product (GDP) per capita is another important variable used in the literature to explain liberty measures, such as civil liberty, economic freedom and democracy (Barro, 1996, 1999; Heid et al., 2012; De Haan and Sturm, 2003; Curran and Wherry, 2003; Gundlach and Paldam, 2009; Rhue and Sundararajan, 2014). In effect, propensity for liberty has been demonstrated to rise with per capita GDP since more prosperous places are more likely to enjoy freedom.

Finally, there are other control factors which have been selected in the literature as explanatory of civil liberty. Population density, commonest languages, origin of the legal system and geographical indicators, joint with religious culture and urban agglomerations, are the most important explanatory variables in references such as Stouffer (1955), who analyses the elements which promote civil liberty using the results provided by a survey, and more recently Barro (1999), Curran and Wherry (2003) and Rhue and Sundararajan (2014).

Following all the referred literature, we have taken into account these variables in our model of civil liberty, in order to control for all of them.

\section{Exploratory Analysis of the Spatial Diffusion of Civil Liberty in the World}

To empirically study the spatial diffusion of civil liberty (CL) and its other conditioning factors, we have chosen to work with the Civil Liberty Gastil index (Freedom House, 2012). Since this index ranges from 1 (most free) to 7 (least free), ${ }^{2}$ following Bollen (1990), we use a simple transformation to construct a normalized index, denoted ICL, ranging from 1, indicating the most civil freedom (Gastil's rank one), to 0, corresponding to the least civil liberties freedom

${ }^{2}$ See Freedom House (2012).

\section{C) PUCP}


(Gastil's rank seven), as follows:

$$
\mathrm{ICL}=\frac{(7-\mathrm{CL})}{6}
$$

When displayed on a map, ICL appears to be spatially clustered. Figures 1 and 2 show the ICL score for countries of the world, and how they changed in the initial and end periods of our sample: 1985 and 2010. When comparing the figures, it is clear that either levels of civil liberty or changes through time show a degree of spatial correlation. The lowest values of the ICL score are observed mainly in Central Africa and most of the Asian countries. At the other end of the distribution, the countries with the highest values of ICL are located in the Western OECD countries, plus Chile and Uruguay. When considering how this spatial pattern changed between 1985 and 2010, there are clear geographic groupings that changed together (e.g., Europe, Central and South America, and in parts of Asia and Africa).

This geographical concentration of similar values of ICL levels across the world's countries is a spatial effect called "spatial autocorrelation". That is, countries with very relatively high/low ICL levels tend to be located in nearby countries with high/low ICL levels more often than would be expected due to random chance. If this is the case, each country should not be viewed as an independent observation and civil liberty will have a geographical spillover effect across countries in the world.

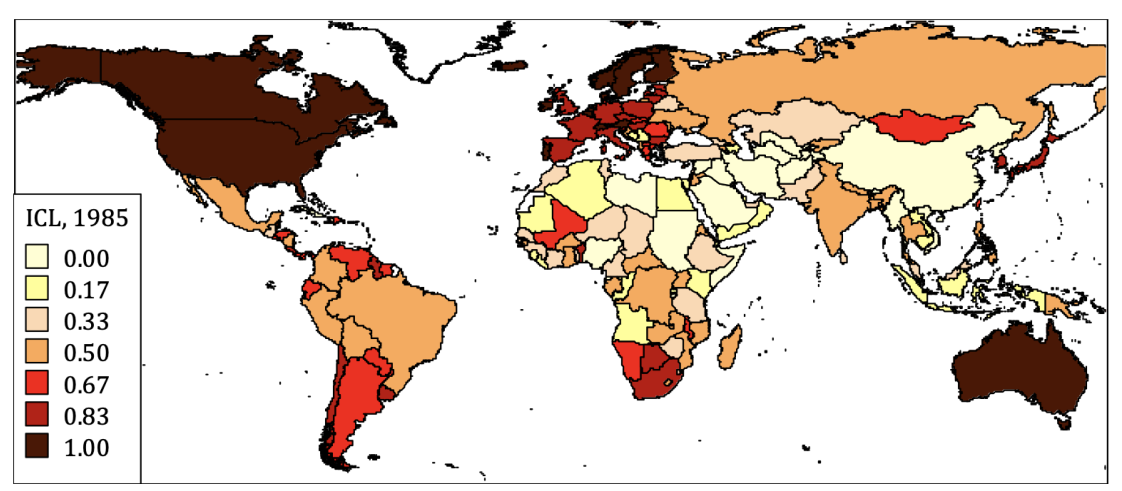

Figure 1. Freedom House Civil Liberties normalized index (ICL) in 1985.

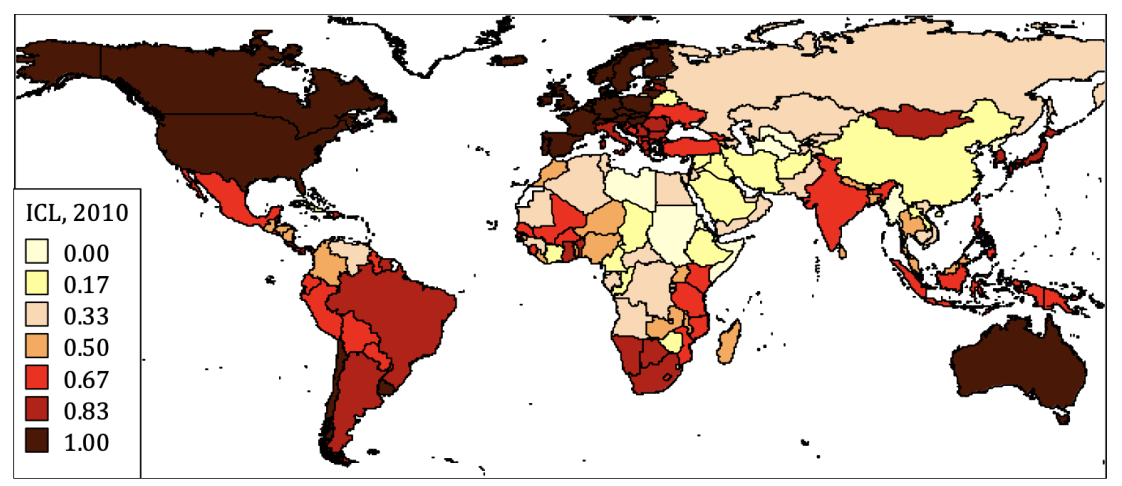

Figure 2. Freedom House Civil Liberties normalized index (ICL) in 2010. 
The spatiotemporal patterns of civil liberty and its dynamics can also be explored using two methods, which are part of a methodology proposed to identify spatiotemporal patterns in the evolution of spatial variables (Vallone and Chasco, 2020). First, we estimate nonparametric kernel density of civil liberty distributions for three different periods to examine the relative civil liberty distributions of the world countries in 1985, 2000 and 2010 (Figure 3). These periods correspond to the start and endpoints of the period plus other important event in world history, the year 2000, which corresponds with the irruption of Internet, as a new public square where individuals express freely and eventually fulfill their believes and opinions.

We consider relative size distributions by normalizing the log of ICL index for each lustrum, divided by the log average size. On the horizontal axis, the value 1 indicates average civil liberty. In 1985, there were a polarization of two country clubs, the largest with values of ICL 50\% below the world average and other group of countries with ICL levels above $100 \%$ of civil liberty average. Compared with 1985, more countries reported values closed to the world average in 2000, providing initial evidence of global convergence in terms of civil liberties. Initial bimodality tends to unimodality in 2010 with an increase in the cluster of free nations.

We continue the exploratory analysis with a view of the spatial dependence and its dynamics by means of the Directional LISA (Local Indicator of Spatial Autocorrelation), which captures the co-movements of countries and neighbors graphically across the Moran scatterplot. ${ }^{3}$ This method visualizes these co-movements by means of the origin-standardized movement vector, obtained by comparing two Moran scatterplots corresponding to two different periods of time, in our case, the first and last period of analysis (Ayouba et al., 2020).

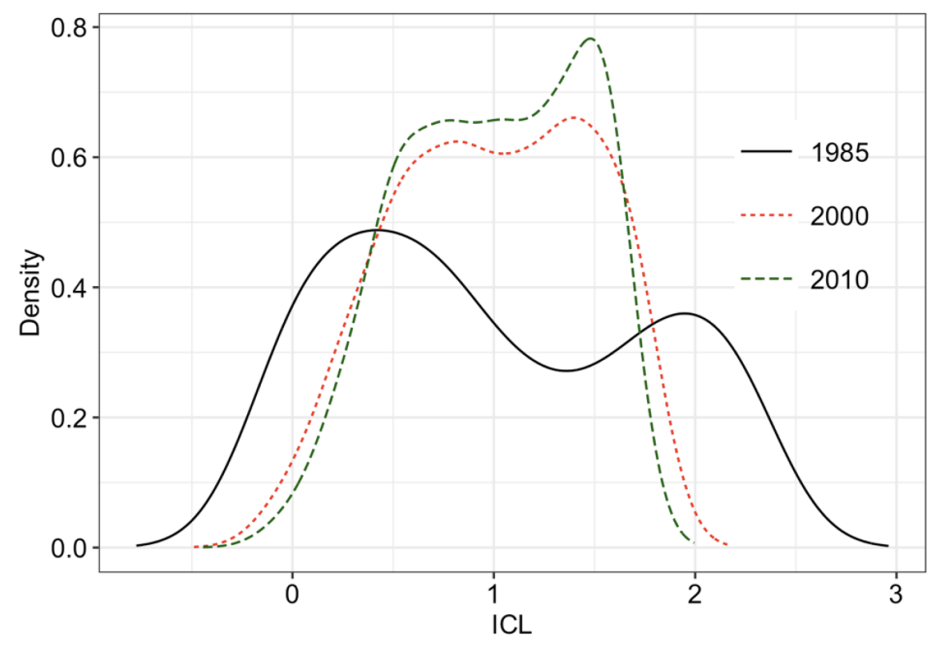

Figure 3. Kernel distributions of the civil liberties normalized indicaror (ICL).

\footnotetext{
${ }^{3}$ The Moran scatterplot consists of four quadrants reporting different types of spatial association between a country's ICL index and that of its neighbors. In the first quadrant are located free nations (countries with a relatively high ICL), neighbored by similar countries ('High-High' or HH). Quadrant two contains countries with relatively low ICL with free neighbors ('Low-High' or LH), while quadrant three contains countries with a relatively low ICL with similar neighbors ('Low-Low' or LL). Finally, in quadrant four are located free nations neighbored by regions with a relatively low ICL ('High-Low' or HL).
} 


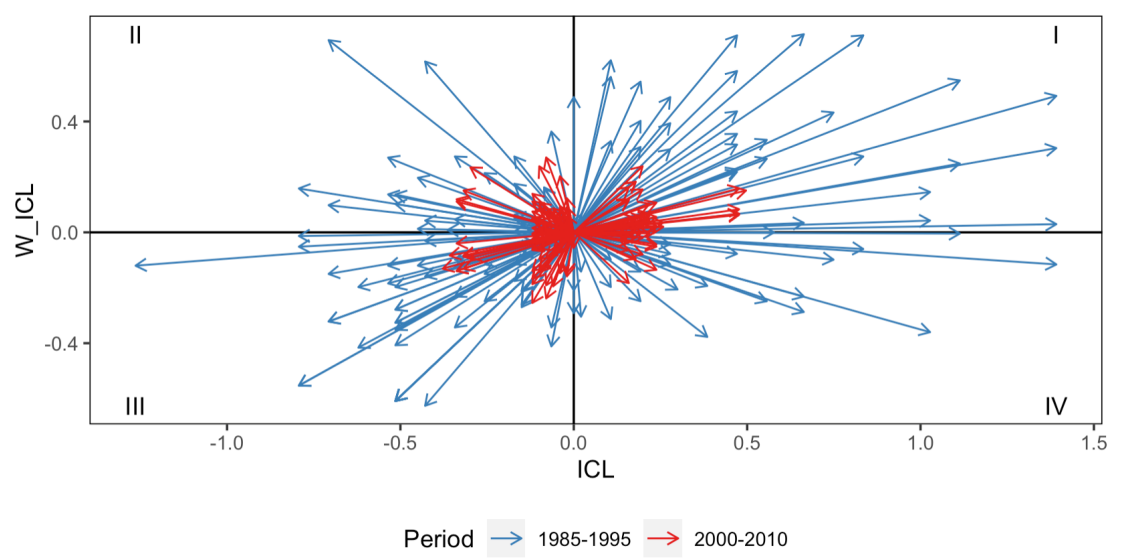

Figure 4. Directional LISA of ICL index for the subperiods 1985-1995 and 2000-2010.

It is a very appropriate technique to test for different dynamics between spatial regimes or subperiods. Figure 4 represents the standardized Directional LISA of these two subperiods: 1985-1995 and 2000-2010. Country neighbor ICL values have been computed with a five nearest neighbor weight matrix. ${ }^{4}$ Several observations can be made from these movements. First, comovements of countries and neighbors in terms of civil liberties are different in shape and size in both subperiods. Specifically, in the second subperiod, co-movements of countries and neighbors are concentrated in the first three quadrants, that is, countries improved or deteriorated their situation along with their neighbors (quadrants I and III), respectively, and there is also a significant number of them that worsen it along with an improvement of their corresponding neighbors (quadrant II). However, it is rarer that, from 2000 to 2010, a country improves its situation in terms of civil liberty together with a deterioration of its neighbors, though there are some exceptions like Angola, Costa Rica and Vietnam, among others, which experienced significant enhancements of their corresponding democratic systems.

Additionally, looking at the length of the line from the origin of the scatterplot to the quadrant position, one can note that the magnitude of co-movements of whatever type is much more important during the first subperiod (1985-1995), particularly in the first quadrant. That is to say, changes in the ICL index were stronger during the last years of the past century, being the improvement in the civil liberty situation ( $1^{\text {st }}$ quadrant) generally stronger than the deterioration one ( $3^{\text {rd }}$ quadrant). Some crucial events at the end of the twentieth century like the 'domino effect' caused by the collapse of the communist regime in 1989 can explain that spatial clusters of countries like the ex-communist Eastern European countries and certain Sub-Saharan African nations experienced such strong improvement in civil liberties.

In the next section, we specify and estimate an econometric model of the ICL endogenous variable, in which we consider - as explanatory variables - the structural conditioning factors: spatial diffusion, religious culture, urban agglomerations in the physical and digital city, economic

\footnotetext{
${ }^{4}$ The spatial weights matrix $(W)$ is of dimension $(N, N)$, for $N$ the number of countries, and it specifies the connectivity structure within the observations in the sample. It has non-zero elements $w_{i j}$ in each row $i$ for those columns $j$ that are neighbors of location $j$. The elements on the diagonal are equal to 0 .
} 


\section{Table 1}

Variable list specification.

\begin{tabular}{|c|c|c|c|}
\hline Variable description & Units & Source & Period \\
\hline \multicolumn{4}{|l|}{ Endogenous variable: } \\
\hline Civil Liberties normalized indicator & $0-1$ index & $\begin{array}{l}\text { Freedom House and } \\
\text { self-elaboration }\end{array}$ & $1985-2010$ \\
\hline \multicolumn{4}{|l|}{ Spatial neighborhood variable: } \\
\hline Civil Liberties spatial lag & $0-1$ index & $\begin{array}{l}\text { Freedom House and } \\
\text { self-elaboration }\end{array}$ & $1985-2010$ \\
\hline \multicolumn{4}{|l|}{ Largest religion explanatory variables: } \\
\hline $\begin{array}{l}\text { Jewish and Christian, Catholic, Protes- } \\
\text { tant, Orthodox Muslim, Buddhist, Hin- } \\
\text { duism, Other. }\end{array}$ & $0-1$ & ARDA & 2008 \\
\hline $\begin{array}{l}\text { Proportion of people belonging to a religion: } \\
\text { Jewish and Christian, Muslim, Buddhist, } \\
\text { Hinduism. }\end{array}$ & $\%$ & World Values Survey & 2009 \\
\hline \multicolumn{4}{|l|}{ City factor explanatory variables: } \\
\hline Population residing in urban areas, $t-5$ & Ratio & United Nations & $1980-2005$ \\
\hline Internet users & Ratio & $\begin{array}{l}\text { International Telecom- } \\
\text { munication Union }\end{array}$ & 1980-2010 \\
\hline \multicolumn{4}{|l|}{ Economic development: } \\
\hline GDP per capita, PPP (constant 2005), $t-5$ & $\begin{array}{l}\text { Internat } \\
\$(\text { in } \operatorname{logs})\end{array}$ & $\begin{array}{l}\text { World Development } \\
\text { Indicators }\end{array}$ & $1980-2005$ \\
\hline \multicolumn{4}{|l|}{ Control explanatory variables: } \\
\hline $\begin{array}{l}\text { a) Socioeconomic variables: } \\
\text { - Population density, } t-5\end{array}$ & $\%$ (in logs) & $\begin{array}{l}\text { World Development } \\
\text { Indicators, GIS }\end{array}$ & $1980-2005$ \\
\hline $\begin{array}{l}\text { - Largest language: Arabic, Chinese, } \\
\text { English, French, Portuguese, Spanish }\end{array}$ & $0-1$ & $\begin{array}{l}\text { ESRI cartographic } \\
\text { database }\end{array}$ & 2010 \\
\hline $\begin{array}{l}\text { - Legal system origin: British, French, } \\
\text { German, Scandinavian, Soviet }\end{array}$ & $0-1$ & La Porta et al. (2008) & 2008 \\
\hline \multicolumn{4}{|l|}{ b) Geographic variables: } \\
\hline - African countries & $0-1$ & GIS $^{*}$ & - \\
\hline - Asian countries & $0-1$ & GIS $^{*}$ & - \\
\hline - Longitude (X-coordinate), capital city & Degrees & GIS $^{*}$ & - \\
\hline - Latitude (Y-coordinate), capita city & Degrees & GIS $^{*}$ & - \\
\hline - Landlocked country & $0-1$ & GIS* & - \\
\hline - Distance to the Equator & $\mathrm{Km}$ & GIS $^{*}$ & - \\
\hline - Distance to the UK & $\mathrm{Km}$ & GIS* & - \\
\hline - Distance to the Netherlands & $\mathrm{Km}$ & GIS* & - \\
\hline - Maximum elevation over the sea level & Meters & GIS $^{*}$ & - \\
\hline - Territorial extension & Mile $\mathrm{Km}^{2}$ & GIS* $^{*}$ & - \\
\hline
\end{tabular}

${ }^{*}$ Self elaboration with a Geographical Information System (GIS).

growth plus some other control variables (see Table 1 for a full description of the model variables). Spatial diffusion is measured as the spatially lagged ICL variable. To measure religion, we have considered the largest religion in each country from ARDA (2011) and the proportion of people belonging to a religious denomination from World Values Survey (2005-2009). Two indicators have been used to measure urban agglomerations: the ratio of population residing in urban areas 
(which proxies the physical city) and the ratio of Internet users (which proxies the digital city). Economic growth is proxied as per capita GDP in natural logarithms.

Additionally, we consider a group of control variables which, according to the previous empirical literature, have been shown to be linked with freedom. In a first group of socioeconomic variables, we include the natural logarithm of population density, the commonest languages and the origin of the legal system, since different legal origins shape national institutions differently (La Porta et al., 2008). In a second group of geographical indicators, we include continental location in Africa and Asia, distances to given world enclaves, such as the Equator, the United Kingdom and The Netherlands, the spatial Earth coordinates of the capital cities, maximum country height above the sea level, territorial extension and landlocked countries.

In this paper, we use a basic sample of 130 countries, which covers the years between 1985 and 2010, as well as an expanded sample of 172 countries for the years between 2000 and 2010 in order to test for structural change at 2000. Additionally, we also use a five-year serial lag for certain regressors like GDP per capita, percentage of urban population and population density, to control - to some extent - for potential endogeneity (reverse causality), as shown in Table 1.

\section{Empirical Model}

We first specify a standard linear pooled regression model, which ignores the panel structure of the data. We estimate this model by Ordinary Least Squares (OLS), in order to test whether a spatial model is more appropriate to describe the data. This model takes the following form for time $t$ :

$$
i c l_{t}=X_{t} \beta_{1}+H \beta_{2}+\varepsilon_{t} ; \varepsilon_{t} \sim \text { i.i.d.N }\left(0, \sigma_{\varepsilon}^{2}\right),
$$

where $i c l_{t}$ is the endogenous variable for $t=1,2, \ldots, T ; X_{t}$ is a $n x k_{1}$ matrix of observations on $k_{1}$ explanatory variables whose values vary over time (urban areas population, Internet users, GDP per capita and population density); $H$ is an $n x k_{2}$ matrix of observations on $k_{2}$ explanatory variables whose values do not vary over time (the other 32 explanatory variables presented in Table 1); and $\varepsilon_{t}$ is the error term, which is supposed to be independent and identically distributed (i.i.d.) following a normal distribution with zero mean, constant variance $\left(\sigma_{\varepsilon}^{2}\right)$ and absence of spatial autocorrelation.

A preliminary estimation of this model for the full set of 36 non-spatial explanatory variables for the sample of 130 countries in the period 1985-2010, leads to a strong multicollinearity problem. ${ }^{5}$ Because of this problem, we have opted to specify a more parsimonious and efficient model, in which fewer explanatory variables are statistically significant. This is the baseline standard linear pooled model $\left(M_{1}\right)$ presented in Table 2. In this first model, the civil liberty index $(\mathrm{icl})$ is set as a function of religion, specifically the largest Muslim, Hindhuism and Animist religions and the percentage of Orthodox believers; the ratio of population residing in urban areas (or the physical city), the ratio of Internet users (or the digital city); and the following group

\footnotetext{
${ }^{5}$ In fact, the multicollinearity conditional number test for this expanded model is 73.6, which is well above the acceptable limit of 30-40 (all computations are available from the authors upon request).
} 
Table 2

Estimation results for the civil liberty index (ICL) model.

\begin{tabular}{|c|c|c|c|c|c|}
\hline \multirow[b]{2}{*}{ Model } & \multirow[b]{2}{*}{$\begin{array}{c}\text { Baseline Standard } \\
\text { Linear Pooled } \\
\left(M_{1}\right)\end{array}$} & \multirow[b]{2}{*}{$\begin{array}{c}\text { Two-way Fixed } \\
\text { Effects Panel Data } \\
\qquad\left(M_{2}\right)\end{array}$} & \multicolumn{3}{|c|}{ Spatial panel data models ${ }^{\ddagger}$} \\
\hline & & & $\begin{array}{l}\text { Two-way } \\
\text { Fixed Effects } \\
\text { SDM }\left(M_{3}\right)\end{array}$ & $\begin{array}{c}\text { Two-way } \\
\text { Fixed Effects } \\
\text { SAR }\left(M_{4}\right)\end{array}$ & $\begin{array}{c}\text { Two-way } \\
\text { Fixed Effects } \\
\text { SAR }\left(M_{5}\right)\end{array}$ \\
\hline \# Countries & 130 & 130 & 130 & 130 & 172 \\
\hline \multirow[t]{2}{*}{ Period } & 6 periods: & 6 periods: & 6 periods: & 4 periods: & 3 periods: \\
\hline & $1985-2010$ & $1985-2010$ & $1985-2010$ & $1985-2000$ & $2000-2010$ \\
\hline Estimation & OLS & LSDV & ML & ML & ML \\
\hline ICL, spatial lag & - & - & $0.38684^{* * *}$ & $0.34582^{* * *}$ & $0.21356^{* * *}$ \\
\hline Urban population, $t-5$ & $0.27947^{* * *}$ & $0.49438^{* * *}$ & $0.49403^{* * *}$ & $0.62845^{* * *}$ & $0.4228^{* *}$ \\
\hline Internet users & $0.14577^{* * *}$ & - & - & - & $0.08281^{* * *}$ \\
\hline GDP per capita, $t-5$ & $0.02697^{* *}$ & - & - & - & $0.04985^{* * *}$ \\
\hline \multicolumn{6}{|l|}{ Control variables: } \\
\hline - Popul. density, $t-5$ & $0.01882^{* * *}$ & $-0.17321^{* * *}$ & $-0.27954^{* * *}$ & $-0.23867^{* * *}$ & - \\
\hline • Muslim religion & $-0.10011^{* * *}$ & - & - & - & - \\
\hline - Hinduism religion & $0.14374^{* * *}$ & - & - & - & - \\
\hline - Animist religion & $-0.16910^{* * *}$ & - & - & - & - \\
\hline - Orthodox $(\%)$ & $-0.12934^{* * *}$ & - & - & - & - \\
\hline - Arabic language & $-0.22821^{* * *}$ & - & - & - & - \\
\hline - Chinese language & $-0.32511^{* * *}$ & - & - & - & - \\
\hline - English language & $0.05794^{* *}$ & - & - & - & - \\
\hline - Spanish language & $-0.09361^{* * *}$ & - & - & - & - \\
\hline - French legal orig. & $-0.05082^{* *}$ & - & - & - & - \\
\hline - African country & $-0.14682^{* * *}$ & - & - & - & - \\
\hline - Asian country & $-0.19597^{* * *}$ & - & - & - & - \\
\hline - Longitude, capital & $-0.00041^{* * *}$ & - & - & - & - \\
\hline - Equator distance & $0.00182^{* *}$ & - & - & - & - \\
\hline Adj. R2 & 0.6269 & 0.8477 & - & - & - \\
\hline Pseudo-R2 & - & - & 0.8642 & 0.8588 & 0.9599 \\
\hline Pool test, country & - & $14.977^{* * *}$ & - & - & - \\
\hline Pool test, time & - & $6.869^{* * *}$ & - & - & - \\
\hline Pool test, two-way & - & $17.046^{* * *}$ & - & - & - \\
\hline Hausman test & - & $31.952^{* * *}$ & - & - & - \\
\hline Spatial Hausman & - & - & $69.500^{* * *}$ & $16.242^{* *}$ & $17.025^{* *}$ \\
\hline Chow: year 2000 & $67.245^{* * *}$ & $44.890^{* * *}$ & - & - & - \\
\hline Robust LM.lag & $13.961^{* * *}$ & - & - & - & - \\
\hline Robust LM.err & $12.837^{* * *}$ & - & - & - & - \\
\hline Moran's I test & $25.252^{* * *}$ & $-0.0653^{* * *}$ & 0.1566 & 0.1684 & 0.1338 \\
\hline
\end{tabular}

*** Significant at $p<0.01 ;{ }^{* *}$ significant at $p<0.05 ;{ }^{*} p<0.1$; OLS: Ordinary Least Squares; LSDV: Least Squares, Dummy Variable; ML: Maximum Likelihood; Adj. R2: adjusted determination coefficient; Pseudo-R2: ratio of the variance of the predicted values over the variance of the observed values for ICL; Rob. LM: Robust Lagrange Multiplier spatial autocorrelation tests for a five nearest-neighbors weight matrix.

${ }^{\ddagger}$ The explanatory variable coefficients are direct impacts.

of control variables: log of per capita GDP, log of population density; Arabic, Chinese, English and Spanish commonest languages, French legal system, African and Asian countries, longitude of the capital city and distance to the Equator. In this set of 17 explanatory variables, there are 4 variables $\left(X_{t}\right)$ whose values vary over time (Internet users, population residing in urban areas, population density and per capita GDP), and 13 variables $(H)$ whose values do not vary over 
time (physical geography, religious culture and legal origin).

As shown in Table 2, all the coefficients are statistically significant at $5 \%$ and $R^{2}$ is equal to 0.6269. The main limitations of this baseline $M_{1}$ model are the presence of spatial autocorrelation in the residuals and the existence of a structural change in 2000, which invalidate and biases the OLS estimation of a pooled model. Other possible bias source could be the coefficient (crosscountry and/or temporal) heterogeneity.

\subsection{Coefficient Cross-Country and Temporal Heterogeneity}

Specification testing in our model involves essentially testing for poolability, for country and/or time unobserved effects, as well as for correlation between these latter and the regressors (Hausman-type tests in Table 2). It is well-known that the simplest poolability test is a standard $F$-test that has as its null hypothesis the OLS pooled model and as its alternative the fixed effects model. Since the fixed effects model estimates the time-invariant country regressors (the group of $32 \mathrm{H}$ variables) as part of the individual effect, we have computed the poolability tests with only those explanatory variables of Model 2 that changes over time (the group of four $X_{t}$ variables). As shown in Table 2, the three poolability tests on country effects, time effects and both country and time effects (two-way), reject the null of constant coefficients. Therefore, the existence of unobserved heterogeneity recommends the specification of a proper panel data model.

Regarding the individual specific effect, the Hausman test (31.952) rejects the null hypothesis of efficiency of the random effects estimator, in favor of a fixed effects model. In addition, the spatial Hausman test, which is appropriate for spatial panel data models (Mutl and Pfaffermayr, 2011; Millo and Piras, 2012) also rejects the null hypothesis in favor of a fixed effects specification for the spatial panel data models $\left(M_{3}, M_{4}\right.$ and $\left.M_{5}\right)$ that have been estimated in this paper. Accordingly, we re-specify the pooled model $\left(M_{1}\right)$ as a two-way fixed effects panel data model $\left(M_{2}\right)$ as follows:

$$
i c l_{t}=X_{t} \beta+\mu_{i}+\lambda_{t}+\varepsilon_{t} ; \varepsilon_{t} \sim i . i . d . N\left(0, \sigma_{\varepsilon}^{2}\right)
$$

where $\mu_{i}$ and $\lambda_{t}$ are the country and time fixed effects, respectively. As in Leeson and Dean (2009) for the study of democracy, our temporal fixed effects control for any features, such as global business cycles, that are common across countries but vary across time. Our country fixed effects control for any permanent differences - mainly in religious culture, legal origin and physical geography - across countries that might be important in contributing to their changes in civil liberty over time. In spite of having controlled for country-specific effects, the estimation of $M_{2}$ by Least Squares Dummy Variable (LSDM) leads to a Moran's I test that is still statistically significant, pointing out to a potential problem of spatial autocorrelation in the OLS residuals.

\subsection{Spatial Autocorrelation}

Spatial autocorrelation in the error term could happen in two cases: when the dependent variable at each location is correlated with observations on the dependent variable at other 
locations and when the error term at each location is correlated with observations on the values for the error term at other locations. In the first case, the omission of spatial autocorrelation will lead to biased OLS estimators and the spatial lag model (SAR model) is the adequate specification since it absorbs the spatial autocorrelation in the error term. In the second case, the consequences of omitting a spatial spillover effect in the error term $(\varepsilon)$, will lead to inefficient OLS estimators. In this case, the spatial error model (SEM) is the correct specification since it incorporates a spatial autoregressive process in the error term $\left(W_{\varepsilon}\right)$.

The standard Lagrange Multiplier (LM) tests proposed by Anselin (1988) and their robust counterparts proposed by Anselin et al. (1996) allow not only acceptance of the null hypothesis (absence of spatial autocorrelation), but also discernment of the alternative basic spatial model if the null is rejected. Both the standard and robust types of LM-tests have two forms, the LM-lag and LM-error, which point to a SAR model or SEM, respectively, in case of refusing the null hypothesis. Only when both tests reject the null hypothesis, must the robust forms of these tests be considered. Typically, only one of them will be significant but in the case that both are highly significant, the model with the largest value for this test will prevail.

The computation of these LM tests on spatial autocorrelation requires the previous selection of a spatial weights matrix $(W)$. Since the consistency and asymptotic normality of the estimators rely on the key assumption that $W$ is strictly exogenous (Manski, 1993), only geographic, distance-based spatial weights should be considered. When the spatial scale of the data analysis is global in nature, distance between two countries should be based on the concept of great circle distance or arc distance on a sphere. ${ }^{6}$

In other similar analysis in the literature, it has been employed a first-order contiguity $W$, in which country neighborhood is defined as having a common geographic border. In our sample, this broadly used matrix is problematic because there are 34 unconnected countries with no neighbors (islands). ${ }^{7}$ Hence, after investigating the robustness of the results to different specifications of $W$, we have selected the five nearest neighbor matrix to estimate the spatially lagged variables in our model. This kind of $W$ is appropriate when the minimum nearest neighbor distance is driven by two pairs of countries that are significantly distant from each other, as it is our case (Fiji and New Zealand are 1,859 miles apart). Since this minimum distance is not representative for the rest of the distribution, a nearest neighbor $W$ will assure the same number of neighbors-in our case, five-for all countries.

In accordance with Elhorst's modeling strategy, when the OLS model is rejected in favor of the SAR or SEM, the spatial Durbin model (SDM) should be first estimated, since it constitutes a generalization of both the SAR and SEM (LeSage and Pace, 2009). Therefore, we re-specify expression (3) as a two-way fixed effects $\mathrm{SDM}\left(M_{3}\right)$ as follows:

\footnotetext{
${ }^{6}$ For the computation of many spatial statistics, and particularly for the estimation of spatial regression models, $W$ should be row-standardized to yield meaningful interpretation of the results. Row standardization consists of dividing each element in a row by the corresponding row sum. Each element in the new matrix thus becomes: $w_{i j}^{*}=w_{i j} / \sum_{j=1}^{N} w_{i j}$, for $N$ the total number of countries in the sample.

${ }^{7}$ Unconnected spatial units (i.e., spatial units for which the corresponding row in the spatial contiguity matrix consists of zeros only) are inappropriate for the computation of many spatial statistics. They also alter the estimation of the spatial autoregressive parameter, since the spatial lag values for these units are zero.
} 


$$
i c l_{t}=\rho W i c l_{t}+X_{t} \beta+W X_{t} \theta+\mu_{i}+\lambda_{t}+\varepsilon_{t} ; \varepsilon_{t} \sim i . i . d . N\left(0, \sigma_{\varepsilon}^{2}\right),
$$

where $W$ is the spatial five nearest neighbors matrix; $\rho$ is the spatial autoregressive coefficient; Wicl is the spatially lagged dependent variable; $W X_{t}$ is the spatially lagged independent variables; $\theta$ represents a $k_{1} x 1$ vector of spatial autoregressive parameters corresponding to the explanatory variables whose values vary over time; while $\varepsilon_{t}$ is the error term, which is assumed to be independent and identically distributed (i.i.d.) following a normal distribution with zero mean, constant variance $\left(\sigma_{\varepsilon}^{2}\right)$ and absence of spatial autocorrelation. The presence of Wicl in the right-hand side of the equation is similar to the inclusion of endogenous variables in the regressor group in systems of simultaneous equations. For this reason, the OLS estimators of the SDM will be biased and inconsistent. As an alternative, we estimate this model by maximum likelihood (ML), as a spatial lag model with explanatory variables $\left[X_{t} W X_{t}\right]$ instead of only $X_{t}$ (Elhorst, 2003, 2010).

Therefore, as shown in Table 2, in this model the civil liberty indicator is explained by three relevant elements: spatial endogenous and/or exogenous interaction-diffusion effects, the physical city (ratio of urban population), and the religious culture joint to other time-constant country fixed effects. The spatial diffusion effect is provided by the spatial autoregressive parameter ( $\hat{\rho}=0.38684)$, which is positive and statistically significant. Hence, an increase of civil liberty levels in one country produced by variations in one or more explanatory variables, will producein average - an increase in this country geographical neighbors' civil liberty levels, and vice versa.

\subsection{Structural Change in the Year 2000}

The statistical non-significance of Internet in the previous model, which covers a sample period of 1985-2010, could be an indication of the existence of a structural change by the year 2000 due to the eruption of Internet as a worldwide phenomenon. In effect, after 2000, Internet was practically circumscribed to the OECD countries and only from 1992, with the development of the World Wide Web, it was accessible to non-academic users. It is during the first decade of the $21^{\text {st }}$ Century that the number of Internet users globally rose from 394 million to 1.858 billion (International Telecomunication Union, 2010). As stated by Rhue and Sundararajan (2014), "digital access has grown dramatically over the world in the last decade".

Hence, the Chow test on structural change has been computed for the fixed effects model being very significant in the year 2000. The results (Table 2) undoubtedly remark the existence of differences in the parameter values for the samples 1985-2000 and 2000-2010. In fact, the estimation of the spatial panel data model for each sub-period leads to a quite different outcome from the overall model (1985-2010). First, both spatial panel data models are no longer SDM but SAR models. Second, the estimation for the period 1985-2000 and 130 countries highlights the importance of the physical city (urban population) and spatial contagion $(\hat{\rho}=0.34582$ ). Third, the estimation for the sub-period 2000-2010 and 172 countries considers that the digital city (Internet) is a significant determinant of civil liberty, somehow in detriment of urban population and mainly, spatial contagion $(\hat{\rho}=0.21356)$. 


\section{Econometric Results}

The most relevant result of our model is the clear and positive significance of the spatial diffusion of civil liberty across neighboring countries during the whole period, though some other interesting conclusions could also be extracted from the control variables.

\subsection{Results on Urban Agglomeration and Religious Culture}

Results in Table 2 highlight the role of urban agglomerations in the city as one of the main explanatory variables of civil liberty. While the physical city, which is measured as the ratio of population living in urban areas, is very significant during the whole period under consideration (particularly in the first part), from 2000 the digital city, proxied by the Internet users ratio, irrupts as a significant determinant of civil liberty differences worldwide. So strong and significant is the appearance of the digital city on civil liberty that the world confronted a clearly structural change at the end of the Twentieth century, which causes a certain decline in the influence of the physical city on civil liberty in favor of the digital city.

Furthermore, the control variable population density - used in our model as a proxy for population growth - is significant with negative sign until 2000 and no longer significant after that date. This negative sign of this variable before 2000 is due to the adverse impact of strong migration flows upon the city time from the world's poor countries. Thereafter, the world's cities began to cope with the influx of population in the cities and consequently, the variable population density loses significance. Interestingly, at the same time the control explanatory variable GDP per capita arises as significant on promoting civil liberties. This outcome could be the result of an economic convergence process among nations by which the poorest nations are the fastest on GDP growth, getting rid of the worst effects of the population pressure.

The econometric results also confirm the important role played by the religious culture, which is included in the country fixed effect variable of the model. However, this effect is not the same in both sub-periods. This is what can be derived from the OLS estimation results of the country fixed effects extracted from the spatial panel data models, on the time-constant explanatory variables of civil liberty (Table 3), which are religion, principal language, legal origin, and physical geography (geo-location) conditions.

Due to the structural change, the results for the overall model (period 1985-2010) are approximately a weighted mean of the estimation results of the two sub-periods. For the first sub-period, there is a clear preponderance of the physical geography indicators in the country fixed effect variable. However, in the second sub-period, the most significant variable on the fixed effect is the religious culture (religions, languages and legal origin), with a special stress in some negative influences for civil liberty, mainly the Islamic and Chinese cultures (proxied by Asian country, Muslim religion, and Arabic and Chinese languages). In line with previous research (Barro, 1999; Gundlach and Paldam, 2009), both Islam and Far East cultures are inversely correlated with the fixed effect (that is, with the ICL index). In other words, it is more difficult for Islam and Far East countries to reach higher levels of civil liberty compared to countries with any other largest religion. 
Table 3

Estimation results for the individual fixed effects on the time-constant regressors.

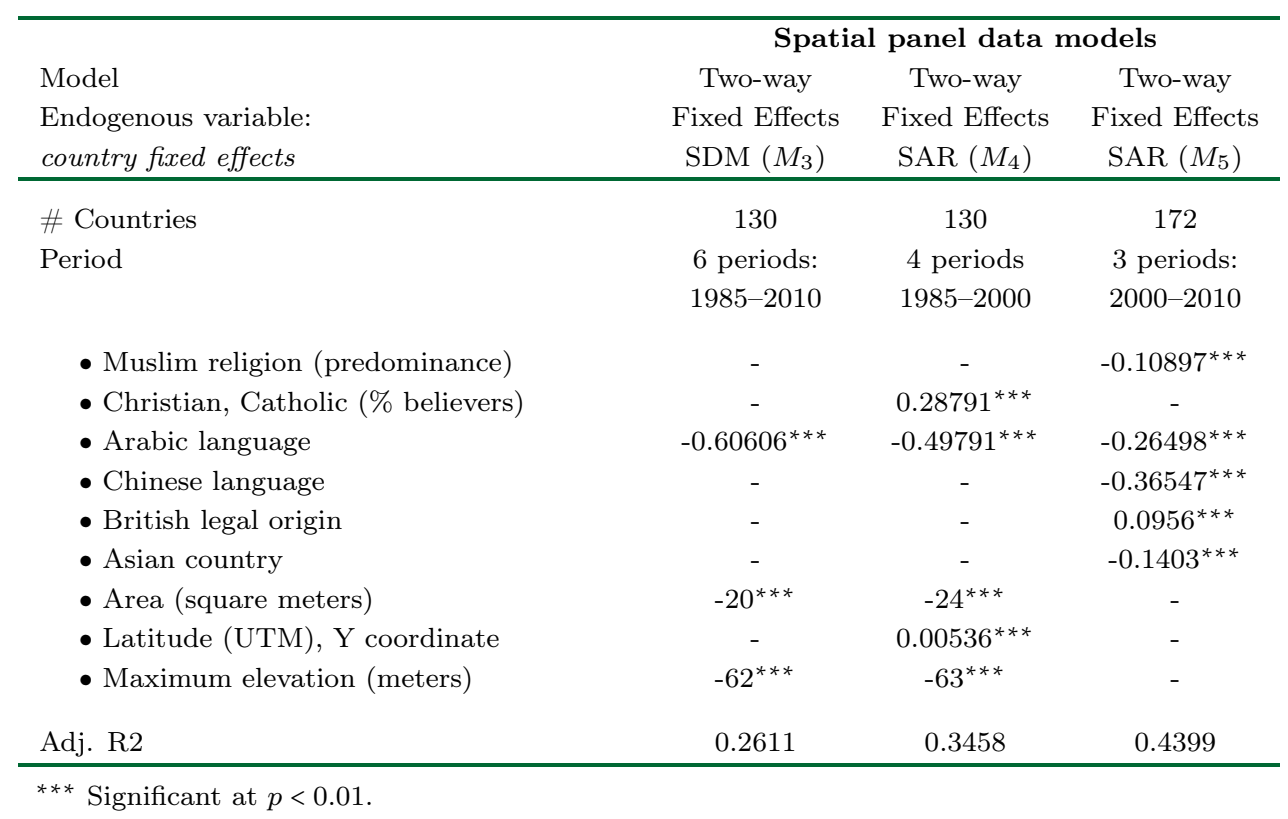

\subsection{Results on Spatial Diffusion of Civil Liberty}

Finally, we present in detail the most relevant result of our model: the clear significance of spatial diffusion of civil liberty across neighboring countries during the period of analysis. As presented in Table 2, the spatial autoregressive parameter $(\hat{\rho})$, which is the rate at which civil liberty spreads, equals to 0.34582 for the first sub-period (1985-2000) and 0.21356 for the second sub-period (2000-2010). Therefore, we can conclude that in the last two decades of the Twentieth Century, countries "caught" almost $35 \%$ of their civil liberty level from neighboring countries. Nonetheless the vertiginous expansion of Internet users, during the present Century, has reduced the spatial (physical) contagion effect of civil liberty in $10 \%$. This result also means that if the average level of the civil liberty index across country $i$ 's neighbors improves by one unit, country $i$ would experience an approximate 0.21 unit upgrading in its civil liberty index. It must be said that this latter result is closer to that obtained in similar studies in the literature, in which the spatial autoregressive parameter ranges from 0.10 to $0.24 .^{8}$

Since the interpretation of the coefficients of the independent variables in the SDM and SAR models is not straightforward, as they do not correspond to marginal impacts (Dall'erba and LeGallo, 2008; LeSage and Pace, 2009), we report the direct impacts for the three spatial panel data models presented in Table 3, which are summary measures of the impact arising from changes in the $i^{\text {th }}$ observation (one determined country) of each variable. This approach

\footnotetext{
${ }^{8}$ For political freedom, Leeson and Dean (2009) found a spatial spread rate between $10 \%$ and $17 \%$, depending upon the model and specification used. For economic freedom, Sobel and Leeson (2007) quantified a spread rate of $20 \%$ and Leeson et al. (2012) concluded that both democracy and economic freedom spread at approximate the same modest rate of $15 \%$. Sobel et al. (2010) studied media freedom spatial contagion detecting a spatial spread rate range of $18-24 \%$ for different spatial samples.
} 
is required by the nature of the matrix inverse, which determines the expected value of the dependent variable: $\hat{y}=\left(I_{N}-\hat{\rho} W\right)^{-1} X \hat{\beta}$, in the case of the SAR model. Since the spatial multiplier $\left(I_{N}-\hat{\rho} W\right)^{-1}$ can be demonstrated to be equivalent to the expansion expression $I_{N}+$ $\hat{\rho} W+\hat{\rho}^{2} W^{2}+\hat{\rho}^{3} W^{3}+\cdots$, the impact of a change in an explanatory variable (say, the ratio of Internet users) for a single country on the level of civil liberty will affect this country itself (a direct impact) and potentially affect all other countries indirectly (an indirect impact), even though two countries are unconnected according to the matrix $W$ (LeSage and Pace, 2009). ${ }^{9}$

Therefore, equilibrium impacts (on civil liberty) of changes in an explanatory variable differ over all observations, since every country has a different degree of connectivity to other countries and different degrees of higher-order connectivities. For this reason, LeSage and Pace (2014) suggest computing the average of the total effects (equilibrium impact) and the average of the direct effects (short-run impact), deriving the indirect effects from the difference between them. These three impacts or effects are presented in Table 4 for all exogenous variables of the SAR model. Both direct and total effects are very significant for all the variables, but indirect effects are not significant at 5\% for urban population, Internet users and GDP per capita during the second sub-period.

The positive estimate for the equilibrium or total impact of urban population in the first subperiod (0.941) is almost $50 \%$ higher than that of second sub-period (0.534). As stated before, this reduction obeys to the appearance of internet and the most important role played by the digital city. This total impact during 2000-2010 is, in turn, about 50\% higher than the short-term impact magnitude (0.628), and $200 \%$ from the indirect or spatial spillover impact based on its scalar impact estimate of 0.313 . The equilibrium impact means that, say, a $50 \%$ increase in the ratio of urban population in a country in time $t-5$ would result in an increase of approximately 0.27 points in the level of the ICL variable in this country in the present time, which constitutes a reduction of the original Gastil's civil liberty (CL) of equation (1) - an improvement in terms of civil liberty - in 1.60 points $(0.534 x 0.50 x 6)$. For the ratio of Internet users, the estimated total

Table 4

Direct, indirect and total impacts for the SAR models.

\begin{tabular}{lcccccc}
\hline & \multicolumn{3}{c}{ Period 1985-2000 } & \multicolumn{3}{c}{ Period 2000-2010 } \\
& $\begin{array}{c}\text { Direct } \\
\text { Impact }\end{array}$ & $\begin{array}{c}\text { Indirect } \\
\text { Impact }\end{array}$ & $\begin{array}{c}\text { Total } \\
\text { Impact }\end{array}$ & $\begin{array}{c}\text { Direct } \\
\text { Impact }\end{array}$ & $\begin{array}{c}\text { Indirect } \\
\text { Impact }\end{array}$ & $\begin{array}{c}\text { Total } \\
\text { Impact }\end{array}$ \\
\hline City variables: & & & & & & \\
Urban population, $t-5$ & $0.628^{* * *}$ & $0.313^{* *}$ & $0.941^{* * *}$ & $0.423^{* *}$ & $0.111^{*}$ & $0.534^{* *}$ \\
Internet users & - & - & - & $0.083^{* * *}$ & $0.022^{*}$ & $0.105^{* * *}$ \\
Control variables: & - & & & & & \\
GDP per capita, $t-5$ & - & - & - & $0.05^{* * *}$ & $0.013^{*}$ & $0.063^{* *}$ \\
Population density, $t-5$ & $-0.239^{* * *}$ & $-0.119^{* *}$ & $-0.358^{* * *}$ & - & - & - \\
\hline
\end{tabular}

*** Significant at $p<0.01 ;{ }^{* *}$ significant at $p<0.05 ;{ }^{*} p<0.1$.

\footnotetext{
${ }^{9}$ Higher-order neighborhood between countries $\left(W^{2}, W^{3}\right.$, etc.) is defined in a recursive fashion, as first-order proximity to countries that are neighbors of the next lower order. For example, Country A would be second-order neighbor to Country C if it is first-order neighbor to Country B, which is itself first-order neighbor to Country A.
} 
impact (0.105) means that the consequence of a rise of $50 \%$ in this variable will be an increase of 0.05 points in the ICL variable, or a decrease of 0.32 points in the original Gastil's CL scale, over $3 / 4$ of which corresponds to a direct effect and the other $1 / 4$ to the spatial spillover, or indirect impact.

Since the equilibrium impacts are average measures, it is possible to compute the individual country-specific equilibrium effect, which can be measured as the total impact over all countries from changing one of the explanatory variables by an amount in one country. Country-specific equilibrium impacts of the explanatory variables are determined by the spatial multiplier since they are defined as $\left(I_{N}-\hat{\rho} W\right)^{-1} \beta$. The spatial multiplier, $\left(I_{N}-\hat{\rho} W\right)^{-1}$, allows determining the most "influential" countries in terms of civil liberty changes; that is, the ones that causes the highest equilibrium impact in civil liberty throughout their respective neighborhoods from changes in the civil liberty levels or the explanatory variables. As shown in Figure 5, the total (direct plus indirect) impact that a change in a country's CL index by one unit over its neighborhood can cause ranges from 1.00 to 1.58 units. These figures are the result of summing down each column of the spatial multiplier matrix. The most influential countries are located in Europe, the Middle East, Southeast Asian Nations, a wide diagonal region from Western to Southeastern African countries, and Central America. On the other side, the countries exerting less influence in their neighborhood are some remote islands, as well as large-sized separated countries. Moreover, the total impact that a simultaneous change in the CL index by one unit in a country's neighborhood is practically constant and equal to 1.27 units. It is the result of summing across each row of the spatial multiplier matrix.

The post-multiplication of the corresponding estimated $\beta$ parameter by the spatial multiplier leads to the total marginal effect or equilibrium impact of each explanatory variable, in each country, on civil liberty. Hence, the total impact that a change in a country's ratio of Internet users by $50 \%$ over its neighborhood causes ranges from 0.25 to 0.39 units of the CL index, while a simultaneous change by $50 \%$ in Internet users in a country's neighborhood produces a more or less constant total effect of 0.31 units. In the case of the ratio of urban population, a change by $50 \%$ in a country causes a total effect over its neighborhood ranging from 1.26 to 1.99 units, while a change by $50 \%$ in a country's neighborhood produces a total effect on this country of 1.60 CL units.

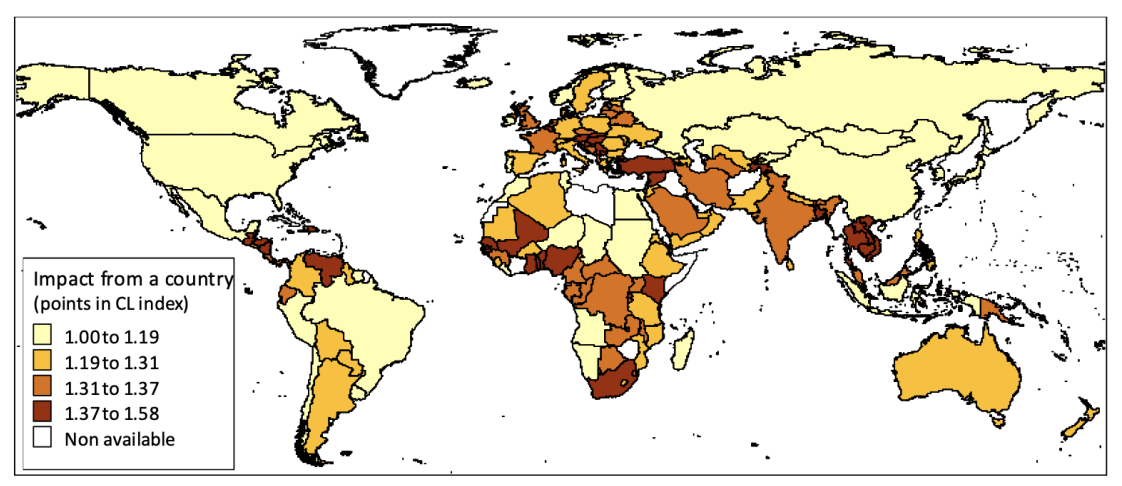

Figure 5. Total effects of a simultaneous change in a country's neighborhood CL index. 
Consequently, as demonstrated previously - in a related study for democracy (Sobel and Leeson, 2007) - only when broad regional changes occur, as in the case of the Arab Spring, the impact on civil liberty is substantial. For example, the impact that a $50 \%$ increase in one of the most influential countries' urban population-Croatia - has on its neighbors ranges from 0 (in many remote countries) to 0.065 (Austria, Bosnia-Herzegovina and Slovenia) on a $1-7$ scale index of civil liberty. However, a simultaneous increase of the ratio of urban population by $50 \%$ in Croatia's neighborhood produces an average improvement of 1.60 units in its Gastil's CL index.

\section{Conclusions}

This paper has focused on exploring studies the existence of spatial diffusion of civil liberty among neighboring countries. For that purpose, we first combine different exploratory space-time analysis approaches to find that this phenomenon is spatially clustered and that a convergence process is at work among the world countries from 1985 to 2010. The empirical results show that there is a structural change by the year 2000 due to the eruption of Internet as a worldwide phenomenon, and this structural change leads to different estimation results before and after the year 2000 .

There is strong evidence that civil liberty spreads across countries during the whole period. The higher the level of CL in a country, the higher it is in its neighbors (and vice versa) due to a spatial spillover effect. Before 2000, civil liberty spreads through geographic space at a rate of $34 \%$ and after this year, this rate reduces to $21 \%$. Hence today, countries "catch" about $21 \%$ of their average geographic neighbors' civil liberty levels. The vertiginous expansion of Internet from 2000 on has reduced the spatial diffusion effect of civil liberty in $10 \%$. It should also be said that the geographical spread of civil liberty has a less impact on neighboring countries with interventions that target only one country compared to the substantial effect caused by widespread regional changes.

The other three important factors explaining civil liberty levels among countries are urban agglomerations in the cities, religious culture and GDP per capita. Physical cities have always been a powerful force in the emergence and diffusion of ideas, and so it is for civil liberty. However, after the year 2000 approximately, with the appearance of internet, the digital city irrupts as the most significant determinant of civil liberty differences worldwide, causing a decline in the influence of the physical city. Regarding religious culture, it also plays an important role in explaining civil liberty levels across countries. We have found that - compared to other societies - civil liberty is less likely for countries with Islamic and Far East cultures. Indeed, as pointed out by the literature, the implementation and diffusion of civil liberty is much more challenging in these countries due to the tight relationship existing between religion and state which provides no legitimacy for autonomous social institutions.

Additionally, there is a substitution of the control variables. During the first sub period, population density is significant with negative sign because the strong migration flows upon the city, being no longer significant from 2000. In contrast, from this year GDP per capita arises as significant on promoting civil liberty. It seems that the economic convergence among nations

\section{PUCP}


by which the poorest nations are the fastest on GDP growth, get rid of the worst effects of the previous population pressure.

Therefore, we can confirm the initial hypothesis in favor of the existence of a spatial diffusion effect in civil liberty across countries. Civil liberty spreads and national frontiers are not a decisive obstacle, except those countries where the Internet is still today restricted. However, it must be said that, though the horizon of civil liberty is expanding day by day, there are multiple elements threatening these achievements, as shown by the Freedom House survey. In fact, during 2010 there were 31 countries registering a decline in their level of civil liberty and only 10 recording gains. The main channels through which civil liberty is transmitted from one place to another are human flows, trade, formal and informal networks and organizations and, more recently, the Internet. For this reason, all these interactions between individuals and countries are of capital importance and should clearly shape the social, economic and political agendas of all countries.

\section{References}

Acemoglu, D., Johnson, S., Robinson, J., and Yared, P. (2008). Income and Democracy. The American Economic Review 98(3), 808-842.

Acemoglu, D., Johnson, S., Robinson, J., and Yared, P. (2009). Reevaluating the modernization hypothesis. Journal of Monetary Economics 56(8), 1043-1058.

Aixalá, J., and Fabro, G. (2009). Economic freedom, civil liberties, political rights and growth: a causality analysis. Spanish Economic Review 11, 165-178.

Alfonso-Gil, J., Lacalle-Calderón, M., and Sánchez-Mangas, R. (2014). Civil liberty and economic growth in the world: a long-run perspective, 1850-2010. Journal of Institutional Economics 10(3), 427-429.

Anselin, L. (1988). Spatial Econometrics: Methods and Models. Dordrecht: Kluwer Academic.

Anselin, L., Bera, A. K., Florax, R., and Yoon, M. J. (1996). Simple diagnostic tests for spatial dependence. Regional Science and Urban Economics 26(1), 77-104.

Association of Religion Data Archives. (2011). Cross-National Socio-Economic and Religion Data 2011. http://www.thearda.com/Archive/Files/Descriptions/ECON11.asp.

Aurigi, A. (2005). Making the Digital City. The Early Shaping of Urban Internet Space. Burlington: Ashgate Publishing Company.

Ayouba, K., Le Gallo, J., and Vallone, A. (2020). Beyond GDP: an analysis of the socio-economic diversity of European regions. Applied Economics 52(9), 1010-1029.

Barro, R. J. (1996). Democracy and Growth. Journal of Economic Growth 1(1), 1-27.

Barro, R. J. (1999). Determinants of Democracy. Journal of Political Economy 107(6), 158-183.

Benyishay, A., and Betancourt, R. R. (2010). Civil liberties and economic development. Journal of Institutional Economics 6(3), 281-304.

Berlin, I. (1958). Two Concepts of Liberty. Oxford: Clarendon Press.

Bollen, K. A. (1990). Political Democracy: Conceptual and Measurement Traps. Studies Comparative International Development 25(1), 7-24. 
Boone, P. (1996). Political and Gender Oppression as a Cause of Poverty. London: Centre for Economic Performance, London School of Economics and Political Science.

Bond, R. M., Fariss, C. J., Jones, J. J., Kramer, A. D. I., Marlow, C., Settle, J. E., and Fowler, J. H. (2012). A 61-million-person experiment in social influence and political mobilization. Nature 489, 295-298.

Carlsson, F., and Lundström, S. (2002). Economic freedom and growth: Decomposing the effects. Public Choice 112, 335-344.

Centola, D., and Macy, M. (2007). Complex Contagions and the Weakness of Long Ties. American Journal of Sociology 113(3), 702-34.

Chokoshvili, D. (2011). The Role of the Internet in the Democratic Transition: Case Study of the Arab Spring. Budapest: Department of Public Policy, Central European University.

Chwe, M. (2003). Rational Ritual: Culture, Coordination, and Common Knowledge. New Jersey, Oxfordshire: Princeton University Press.

Cole, J. S. (2003). The Contribution of Economic Freedom to World Economic Growth: 1980-99. Cato Journal 23(2), 189-198.

Compton, R. A., Giedeman, D. C., and Hoover, G. A. (2011). Panel evidence on economic freedom and growth in the United States. European Journal of Political Economy 27(3), 432-435.

Curran, S. R., and Wherry, F. F. (2003). Do Transnational Organizations Promote Civil and Political Liberties? Cross-National Evidence from Southeast Asia, 1978-2002. Working Paper Series. Center for Migration and Development, Princeton University.

Dall'erba, S., and LeGallo, J. (2008). Regional convergence and the impact of European structural funds over 1989-1999: A spatial econometric analysis. Papers in Regional Science 87(2), 219-244.

Dawson, J. W. (2003). Causality in the freedom-growth relationship. European Journal of Political Economy 19(3), 479-495.

De Haan, J., and Sturm, J. E. (2000). On the relationship between economic freedom and economic growth. European Journal of Political Economy 16(2), 215-241.

De Haan, J., and Sturm, J. E. (2003). Does more democracy lead to greater economic freedom? New evidence for developing countries. European Journal of Political Economy 19(3), $547-563$.

De Long, J. B., and Shleifer, A. (1993). Princes and Merchants: European City Growth Before the Industrial Revolution. Journal of Law and Economics 36(2), 671-702.

Dornbusch, R., Park, Y. C., and Claessens, S. (2000). Contagion: Understanding How It Spreads. The World Bank Research Observer 15(2), 177-197.

Doucouliagos, C., and Ulubasoglu, M. A. (2006). Economic freedom and economic growth: Does specification make a difference? European Journal of Political Economy 22(1), 60-81.

Eisenstadt, S. N. (1968). The Protestant Ethic. Theses in the Framework of Sociological Theory and Weber's Work. In S. N. Eisentadt (Ed.), The Protestant Ethic and Modernization: A Comparative View (pp. 3-45). New York: Basic Books.

Elhorst, J. P. (2003). Specification and Estimation of Spatial Panel Data Models. International 
Regional Sciences Review 26(3), 244-268.

Elhorst, J. P. (2010). Applied Spatial Econometrics: Raising the Bar. Spatial Economic Analysis $5(1), 9-28$.

Freedom House. (2012). Freedom in the World 2012. http://www.freedomhouse.org/report/ freedom-world/freedom-world-2012.

Greif, A. (2004). Institutions: Theory and History. Cambridge: Cambridge University Press.

Gundlach, E., and Paldam, M. (2009). A farewell to critical junctures: Sorting out long-run causality of income and democracy. European Journal of Political Economy 25(3), 340354.

Haynes, J. (2013). Religion, Democracy and Civil Liberties: Theoretical Perspectives and Empirical Ramifications. European Political Science 12(2), 171-183.

Heckelman, J. C. (2000). Economic Freedom and Economic Growth: A Short-Run Causal Investigation. Journal of Applied Economy 3(1), 71-91.

Heid, B., Langer, J., and Larch, M. (2012). Income and democracy: Evidence from system GMM estimates. Economics Letters 116(2), 166-169.

Huntington, S. P. (1996). The Clash of Civilizations and the Remaking of World Order. New York: Simon and Schuster.

International Telecommunication Union. (2010). The World in 2010: ICT Facts and Figures. http://www.itu.int/ITU-D/ict/statistics/.

Isham, J., Kaufmann, D., and Pritchett, L. (1997). Civil Liberties, Democracy, and the Performance of Government Projects. The World Bank Economic Review 11(2), 219-42.

Justesen, M. (2008). The effect of economic freedom on growth revisited: New evidence on causality from a panel of countries 1970-1999. European Journal of Political Economy $24(3), 642-660$.

Kelejian, H. H., Murrell, P., and Shepotylo, O. (2013). Spatial spillovers in the development of institutions. Journal of Development Economics 101, 297-315.

King, R., and Levine, R. (1993). Finance and Growth: Schumpeter Might be Right. Quarterly Journal of Economics 108(3), 717-737.

Kormendi, R., and Meguire, P. G. (1985). Macroeconomics Determinants of Growth: CrossCountry Evidence. Journal of Monetary Economics 16(2), 141-163.

Landes, D. (1998). The Wealth and Poverty of Nations. New York: W. W. Norton.

La Porta, R., Lopez de Silanes, F., Shleifer, A., and Vishny, R. W. (1999). The Quality of Government. Journal of Law, Economics and Organization 15(1), 222-279.

La Porta, R., Lopez de Silanes, F., and Shleifer, A. (2008). The Economic Consequences of Legal Origins. Journal of Economic Literature 46(2), 285-332.

Leeson, P. T., and Dean, A. M. (2009). The Democratic Domino Theory: An Empirical Investigation. American Journal of Political Science 53(3), 533-551.

Leeson, P. T., Sobel, R. S., and Dean, A. M. (2012). Comparing the spread of capitalism and democracy. Economics Letters 114(1), 139-141.

Lewczuk, A. (2020). Are civil liberties contagious? Analysis of determinants of de facto civil rights protection in post-socialist countries. Constitutional Political Economy 32, 187-217. 
LeSage, J. P., and Pace, R. K. (2009). Introduction to Spatial Econometrics. Boca Raton: Taylor and Francis.

LeSage, J. P., and Pace, R. K. (2014) Interpreting Spatial Econometric Models. In M. Fischer and P. Nijkamp (Eds.), Handbook of Regional Science (pp. 1535-1552). Berlin, Heidelberg: Springer.

Lipset, S. M. (1994). The Social Requisites of Democracy Revisited: 1993 Presidential Address. American Sociological Review 59(1), 1-22.

Manski, C. F. (1993). Identification of Endogenous Social Effects: The Reflection Problem. Review of Economic Studies 60(3), 531-542.

McCloskey, D. (2010). Bourgeois Dignity: Why Economics Can't Explain the Modern World. Chicago: The University of Chicago Press.

Millo, G., and Piras, G. (2012). splm: Spatial Panel Data Models in R. Journal of Statistical Software 47(1), 1-38.

Minogue, K. (2012). Politics: A Very Short Introduction. New York: Oxford University Press.

Mutl, J., and Pfaffermayr, M. (2011). The Hausman test in a Cliff and Ord panel model. Econometrics Journal 14(1), 48-76.

Nair, P. S. (2011). Introduction. In P. S. Nair (Ed.), Human Rights in a Changing World (pp 21-35). Delhi: Kalpaz Publications.

Natharaj, P. S. V. (2011). Roots of Human Rights Principles: A Scan of the Sacred Texts. In P.S. Nair (Ed.), Human Rights in a Changing World (pp. 82-96). Delhi: Kalpaz Publications.

North, D. C. (1995). The Paradox of the West. In R. W. Davis (Ed.), The Origins of Modern Freedom in the West (pp 7-34). Standford: Stanford University Press.

North, D. C., and Weingast, B. R. (1989). Constitutions and Commitment: The Evolution of Institutions Governing Public Choice in Seventeenth-Century England. The Journal of Economic History 49(4), 803-832.

O'Loughlin, J., Ward, M. D., Lofdahl, C. L., Cohen, J. S., Brown, D. S., Reilly, D., Gleditschk, K. S., and Shin, M. (1998). The Diffusion of Democracy, 1946-1964. Annals of the Association of American Geographers 88(4), 545-574.

Palmer, R. R. (1959). The Age of the Democratic Revolution: A Political History of Europe and America, 1760-1800. New Jersey: Princeton University Press.

Peckham, R. (2013) Economies of contagion: financial crisis and pandemic. Economy and Society 42(2), 226-248.

Pick, J., Sarkar, A. and Parrish, E. (2020). The Latin American and Caribbean digital divide: a geospatial and multivariate analysis. Information Technology for Development 27(2), 235-262.

Rhue, L. and Sundararajan, A. (2014). Digital access, political networks and the diffusion of democracy. Social Networks 36, 40-53.

Sobel, R. S., Dutta, N., and Roy, S. (2010). Beyond Borders: Is Media Freedom Contagious? Kyklos 63(1), 133-143.

Sobel, R. S., and Leeson, P. T. (2007). The Spread of Global Economic Freedom. In J. Gwartney and R. Lawson (Eds.), Economic Freedom of the World: 2007 Annual Report (pp 29-37). 
Vancouver: The Fraser Institute.

Stouffer, S. A. (1955). Communism, Conformity and Civil Liberties. New York: Doubleday.

Tabellini, G. (2008). Presidential Address: Institutions and Culture. The Journal of the European Economic Association 6(2-3), 255-294.

Tausch, A., and Heshmati, A. (2010). Learning from Latin America's experience: Europe's failure in the "Lisbon Process". IZA Discussion Paper No. 4779.

Vallone, A., and Chasco, C. (2020). Spatiotemporal methods for analysis of urban system dynamics: an application to Chile. Annals of Regional Science 64, 421-454

Ward, M. D., and Gleditsch, K. S. (2008). An Introduction to Spatial Regression Models in the Social Sciences. California: SAGE Publications.

Weber, M. (2002). The Protestant Ethic and the Spirit of Capitalism: and Other Writings. London: Penguin Books.

World Values Survey. (2005-2009). WVS Wave 5 2005-2009 Official Aggregate v.20140429. https: //www.worldvaluessurvey.org/WVSOnline.jsp.

Wright, R. (1992). Islam, Democracy and the West. Foreign Affairs 71(3), 131-45.

Zhuo, X., Wellman, B., and Yu, J. (2011). Egypt: The First Internet Revolt? Peace Magazine $27(3), 6-10$. 